\title{
EDUCAÇÃO AMBIENTAL: UMA PROPOSTA DE INTERVENÇÃO PEDAGÓGICA NA RESERVA ECOLÓGICA AMADEU BOTELHO NO MUNICÍPIO DE JAÚ
}

\author{
ENVIRONMENTAL EDUCATION: A PROPOSAL FOR INTERVENTION \\ PEDAGOGICAL PROGRAM IN AMADEU BOTELHO \\ JAÚ CITY
}

\section{EDUCACIÓN AMBIENTAL: UNA PROPUESTA DE INTERVENCIÓN PEDAGÓGICA EN LA RESERVA ECOLÓGICA AMADEU BOTELHO EN LA CIUDAD DE JAÚ}

\author{
Gabriela Betto Muzolon \\ Licenciatura em Pedagogia - Faculdade Integradas de Jaú \\ Email: gabibetto1@gmail.com \\ Gabriele Priscila Dias \\ Licenciatura em Pedagogia - Faculdades Integradas de Jaú \\ E-mail: gabrielepd@hotmail.com \\ Célia Regina Auler Pereira Furuta \\ Mestre em Educação para a Ciência - UNESP \\ Docente das Faculdades Integradas de Jaú \\ E-mail: crfuruta@gmail.com
}

\section{RESUMO}

Considerando a evolução histórica de nossa sociedade, ao chegarmos ao século XXI nos deparamos com uma grave crise civilizatória e planetária proveniente de processos de produção e consumo descontrolados e excessivos. Nessas premissas, ao longo desse período a Educação Ambiental foi se constituindo como uma estratégia importante no intuito de otimizar uma relação homem-natureza de maneira sustentável, que o possibilite a sentir-se com parte integrante do meio e esteja conscientizado para o enfrentamento dos problemas ambientais tão agravantes e atuais na história da humanidade. Para o desenvolvimento do projeto optou-se pela Reserva Ecológica Amadeu Botelho, situada no município de Jaú, pois esta constitui um espaço de educação não formal, onde se desenvolve ações educativas através do Projeto Curumim, visando aproximar os visitantes da vida natural e a sensibilização para a preservação do meio. Portanto objetivou-se desenvolver uma proposta de atividades lúdicas, de modo a dar suporte às visitas monitoradas que acontecem no local, utilizando os recursos naturais da reserva como ferramenta de ensino aprendizagem, no intuito de estimular atitudes preservacionistas e consciência ecológica dos visitantes. Para desenvolver o estudo foram realizadas visitas para análise do ambiente natural, bem como pesquisa bibliográfica baseada em livros, artigos, dissertações e teses disponíveis em meio eletrônico. Conclui-se que os espaços naturais são aspectos fundamentais para desenvolvimento de uma consciência ecológica e o despertar para a prática de cidadania visando a sustentabilidade planetária. Houve uma evolução com relação a legislação sobre Educação Ambiental e que esta deve ser desenvolvida em caráter formal, contínuo e permanente, de forma interdisciplinar, bem como de maneira não formal e informal. Palavras-chave: Educação Ambiental. Práticas educativas. Relação homem-natureza. 


\begin{abstract}
Considering the historical evolution of our society, as we approach the 21 st century we face a serious civilizing and planetary crisis arising from uncontrolled and excessive production and consumption processes. On these premises, over this period Environment Education has been constituted as an important strategy in order to optimize a sustainable relationship between man and nature, enabling it to feel part of the environment and be aware of the confrontation of environmental problems so aggravating and present in the history of mankind. For the development of the Project the Amadeu Botelho Ecological Reserve, located in the municipality of Jaú, as this is a non-formal education space, where educational activities are developed through the Curumim Project, aiming to bring visitors closer to the natural life and awareness to preservate the reserve. Therefore, the objective was to develop a proposal of playful activities, in order to provide support for monitored visits taking place on the spot, using the natural resources of the reserves as a teaching and learning tool in order to stimulate preservationists atitudes and ecological awareness of the visitors. To develop the study were visits gere made for analysis of the natural environment, as well as bibliographic research based in books, articles, dissertations and theses available electronically. It is observed that the Natural spaces are fundamental aspects for the development of an awareness and the awakening to the practice of citizenship aiming at planetary sustainability. There was evolution with regard to legislation on environmental education and that it should be developed on a formal, continuous and permanent basis, in an interdisciplinary manner, as well as non-formally and informally.
\end{abstract}

Keywords: Environmental Education. Educational practices. Man-nature relationship.

\title{
RESUMEN
}

Considerando la evolución histórica de nuestra sociedad, a medida que nos acercamos al siglo XXI nos enfrentamos a una grave crisis civilizadora y planetaria derivada de procesos de producción y consumo incontrolados y excesivos. La Educación Ambiental se ha constituido como una estrategia importante para optimizar una relación sostenible entre el hombre y la naturaleza, permitiéndole sentirse parte integral del medio ambiente y ser consciente de la confrontación de los problemas ambientales más agravantes y actuales de la historia de la humanidad. La Reserva Ecológica Amadeu Botelho, ubicada en el municipio de Jaú, es un espacio educativo no formal, donde se realizan actividades educativas a través del Proyecto Curumim, acercando a los visitantes a la vida natural y a la conciencia de la preservación del medio ambiente. El objetivo era presentar una propuesta de actividades lúdicas, con el fin de apoyar las visitas monitoreadas que tienen lugar en el sitio, utilizando los recursos naturales de la reserva como una herramienta de enseñanza y aprendizaje, estimulando las actitudes conservacionistas y la conciencia ecológica de los visitantes. Para desarrollar el estudio se realizaron visitas de análisis del entorno natural, así como investigación bibliográfica basada en libros, artículos, disertaciones y tesis disponibles en medios electrónicos. Se concluye que ha habido una evolución con respecto a la legislación sobre Educación Ambiental y que debe ser desarrollada por la educación formal e informal de manera permanente e interdisciplinaria. Palabras clave: Educación ambiental. Prácticas educativas. Relación hombre-naturaleza.

\section{INTRODUÇÃO}

Considerando toda a evolução histórica de nossa sociedade e ao chegarmos ao século XXI nos deparamos com uma grave crise civilizatória e planetária proveniente de processos e produção e consumo descontrolados e excessivos, fundamentados em concepções e atitudes 
antropocêntricas e utilitaristas em relação à natureza, como se os recursos naturais fossem infinitos e essas ações nenhum mal resultaria para os seres viventes no planeta.

$\mathrm{Na}$ década de 50, impulsionado por avanços tecnológicos, o homem ampliou sua capacidade de produzir alterações no ambiente natural, notadamente nos países mais desenvolvidos, e na década seguinte seus efeitos negativos sobre a qualidade de vida já eram evidentes. No entanto, nos primeiros anos da década de 60, os problemas ambientais começaram a constituir a pauta de muitos eventos em vários lugares do mundo, momento em que questionamentos surgiram decorrentes da ação do homem como industrialização acelerada, poluição ambiental, crescimento demográfico, escassez de alimentos, esgotamento dos recursos naturais, aparecimento de novas doenças, entre tantos outros.

Partindo desse pressuposto, a Educação Ambiental foi se constituindo como uma estratégia importante para o enfrentamento dos problemas ambientais tão agravantes e atuais na história da humanidade, no intuito de otimizar uma relação homem- natureza de maneira sustentável. Essa educação se propagou em nosso meio com o objetivo de fomentar conhecimentos necessários para a interpretação dos fenômenos que moldam o meio ambiente, e para a promoção de valores éticos, econômicos e estéticos que constituem a base do autocontrole, estimulando comportamentos compatíveis com a conservação e melhoria da qualidade ambiental. Ou seja, tornou-se um processo de construção da relação humana com o ambiente, em que o princípio de responsabilidade, da autonomia, da democracia, entre outros pudesse estar presente, possibilitando minimizar ou solucionar problemas ambientais. Salientase, entretanto que a Declaração de Estocolmo de 1972 foi o primeiro documento oficial a tratar da interação entre os seres humanos e o meio ambiente e a sinalizar a ética como meio para a interação entre os seres humanos, o ambiente e os recursos naturais.

No Brasil, a Educação Ambiental vem se consolidando como espaço de debates e realizações, sobretudo por se constituir em um campo institucionalizado pela Lei Federal $\mathrm{n}^{\mathbf{o}}$ 9795/99 que estabelece a Política Nacional de Educação Ambiental, associada a temática dos direitos humanos.

Partindo desses pressupostos e elencando as diretrizes estabelecidas pela referida lei, observa-se que a Reserva Ecológica Amadeu Botelho no Município de Jaú configura um amplo espaço com fins educativos para exploração da natureza, destacando-se a fauna e flora local, bem como as atividades produtivas de forma convencional e orgânica. Nessas premissas, pretendeu-se desenvolver um projeto pedagógico com o intuito de melhor aproveitamento daquele espaço natural, no sentido de promover um processo de ensino e aprendizagem 
significativa para os alunos, por meio de ações educativas, , elencando o desenvolvimento de aspectos como: Consciência, Conhecimento, Comportamento, Habilidades e Participação, sendo que os mesmos constituem os objetivos fundamentais da Educação Ambiental. Outro aspecto a ser considerado e teve como objeto de estudo foi viabilizar uma proposta de atividade prática monitorada, relacionando o conteúdo com a prática educativa em sintonia com a realidade social, econômica, política, cultural e ecológica de nossa região.

Para o desenvolvimento desse estudo, foram realizadas pesquisas bibliográficas em livros, teses, dissertações e publicações científicas em meio eletrônico, abarcando as áreas de Educação, Educação Ambiental e Direitos Humanos. Bem como foram elaboradas as propostas de atividades, de acordo com perspectivas que se pretende não apenas mostrar a compreensão da complexidade da condição humana e do papel da Educação Ambiental, mas também de apontar metodologias de ensino que contemplem habilidades e valores inerentes a prática educativa e a formação de indivíduos aptos a realizar atos de cidadania. Pois, acredita-se que, pequenas interferências podem favorecer a formação de uma teia de comprometimento partindo de ações individuais, capazes de fortalecerem-se formando um novo homem que não mais subestima o meio natural e destrói, mas que seja capaz de perceber-se como parte integrante da natureza e por essa razão preserve o que está a sua volta.

\section{EDUCAÇÃO AMBIENTAL}

A Educação Ambiental é definida pela Organização das Nações Unidas para a Educação, Ciência e Cultura (UNESCO, 1980) como um processo de reconhecimento de valores e clarificação de conceitos, com objetivo de desenvolver habilidades e mudanças de atitudes das pessoas, para que estas entendam e apreciem as relações entre os seres humanos, suas culturas e seu meio biofísico, através de um enfoque interdisciplinar. Ela está relacionada à prática de tomadas de decisões e ética para melhoria da qualidade de vida, devendo atingir pessoas de todas as idades e de todos os níveis sociais, seja através do ensino formal ou não formal, de contínua e permanente.

Para Zeppone (1999) a Educação Ambiental, não se restringe a discutir apenas sobre o meio ambiente, mas as complexas relações de interdependência entre os diversos elementos da natureza, da qual fazemos parte e somos capazes de conhecer e transformar. Entretanto, é preciso entender também que nós não nos relacionamos com a natureza apenas como indivíduos, mas principalmente por meio do trabalho e de outras práticas sociais, e que as relações de todos nós com ela tem dimensões econômicas, políticas, sociais e ambientais . 
Dias (1999, p. 28) categoriza como objetivos da Educação Ambiental, alguns aspectos de representam a essência para formação de valores e atitudes ecologicamente corretas.

1.Consciência...ajudar os indivíduos e grupos sociais a sensibilizaremse e a adquirirem consciência do meio ambiente global e suas questões; 2.Conhecimento...a adquirirem diversidade de experiências e compreensão fundamental sobre o meio ambiente e seus problemas;

3.Comportamento...a comprometerem-se com uma série de valores, a sentirem interesse pelo meio ambiente, e participarem da proteção e melhoria do ambiente;

4.Habilidades...adquirirem as habilidades necessárias para identificar e resolver problemas ambientais;

5.Participação...proporcionar a possibilidade de participarem ativamente das tarefas que têm por objetivo resolver os problemas ambientais (grifo do autor).

A Educação Ambiental tem uma longa trajetória e nesse percurso destaca-se alguns marcos importantes.

A Conferência de Estocolmo 1972, organizada pelas Nações Unidas sobre o Ambiente Humano, é considerada o primeiro marco importante sobre o tema, pois insere e atribui a temática da necessidade de uma educação voltada para as questões ambientais. Concomitantemente a esse evento, o Clube de Roma (coletivo de países ricos economicamente) publicava um documento reflexivo que denunciava o provável colapso da humanidade. Este alerta foi reconhecido posteriormente, após os debates gerados pela "Declaração da ONU sobre o Ambiente Humano" e seu "Plano de Ação Mundial", sendo que nesse documento havia a recomendação sobre a necessidade de capacitação de professores e o desenvolvimento de novos métodos e recursos instrucionais para a Educação Ambiental (PEDRINI, 1997)

Essa Declaração da Organização das Nações Unidas (ONU) sobre o Ambiente Humano reúne 23 princípios que visam a preservação e melhoria do ambiente humano, sendo que o princípio 1 estabelece que:

O homem tem o direito fundamental à liberdade, à igualdade ao desfrute de condições de vida adequadas, em um meio ambiente de qualidade tal que lhe permita levar uma vida digna e gozar de bem-estar, e é portador solene da obrigação de proteger e melhorar o meio ambiente, para as gerações presentes e futuras. A esse respeito, as políticas que promovem ou perpetuam o apartheid, a segregação racial, a discriminação, a opressão colonial e outras formas de opressão e de dominação estrangeira permanecem condenadas e devem ser eliminadas (DIAS, 2004, p. 47).

Outro marco representativo para a Educação Ambiental foi a Conferência Rio-92, que aconteceu na cidade do Rio de Janeiro promovida pela ONU no intuito de ressaltar as questões 
sobre Meio Ambiente e o Desenvolvimento, além de fortalecer as premissas da Conferência de Tbilisi ocorrida em 1977.Esta teve como objetivo examinar a situação ambiental do mundo e as mudanças ocorridas depois da Conferência de Estocolmo em 1972. Além de identificar estratégias regionais e globais para ações referentes às principais questões ambientais, bem como recomendar medidas a serem tomadas, nacional e internacionalmente referentes à proteção ambiental através de política de desenvolvimento sustentado; promover o aperfeiçoamento da legislação ambiental internacional e examinar estratégias de promoção do desenvolvimento sustentável e da eliminação da pobreza nos países em desenvolvimento (DIAS, 2004).

Em 1988 foi promulgada a nova Constituição Federal Brasileira , com um capítulo dedicado ao Meio Ambiente trazendo avanços significativos na área ambiental e sendo considerada entre as leis mais completas do mundo, especialmente no que se refere às questões ambientais, fato que configura um marco importante principalmente para o Brasil (DIAS, 2004).

O artigo 225 da referida Constituição pressupõe que "Todos têm direito ao meio ambiente ecologicamente equilibrado, bem de uso comum do povo e essencial à sadia qualidade de vida, impondo-se ao Poder Público e à coletividade o dever de defendê-lo e preservá-lo para as presentes e futuras gerações”. Esse mesmo documento apregoa a função do poder público, sendo: "Promover a Educação Ambiental em todos os níveis de ensino e a conscientização pública para a preservação do meio ambiente" (BRASIL, 1988, p. 170).

A partir de 1989, todos os estados e municípios revisaram suas leis maiores, alicerçados nas propostas da Constituição Federal, incluindo um capítulo do meio ambiente com referência à Educação Ambiental (MAIAKOVSKI, 1998).

Conforme Strong (1998), em 1997, foi lançado os Parâmetros Curriculares Nacionais (PCN's), que pela primeira vez, deram indicações de como incorporar a dimensão ambiental na forma de Tema Transversal nos currículos do Ensino Fundamental.

Considerando que a legislação brasileira está fundamentada nos princípios da Declaração Universal dos Direitos Humanos a qual sublinha em seu artigo $1^{\text {o }}$ que: "Todos os homens nascem livres e iguais em dignidade e direitos. São dotados de razão e consciência e devem agir em relação uns aos outros com espírito de fraternidade" (ONU, 1948).

A conquista dos direitos humanos foi a base na qual todos os demais direitos se apoiaram entre eles a Declaração dos Direitos da Criança aprovada pela ONU, em 20 de Novembro de 1959. As crianças demandam uma proteção específica atenta à sua vulnerabilidade e fragilidade 
diante do mundo adulto, a violência, a exploração do trabalho infantil e a prostituição de jovens precisavam ser interditadas por meio de regras que se alinhavam àquelas estabelecidas nos direitos humanos. Foi instituída assim uma nova forma de infância, protegida dos espaços dos adultos, dedicada ao desenvolvimento da criança e em sua preparação para o exercício da cidadania (TIRIBA; PROFICE, 2014).

Segundo Tiriba (2014) o tempo dedicado às atividades ao ar livre como brincar, explorar e pesquisar, assim como as condições concretas para desfrutar de ambientes ao ar livre, deveriam ser componentes obrigatórios tanto dos planejamentos pedagógicos e das rotinas, quanto dos próprios espaços onde acontecem as atividades escolares. A escola sendo o único espaço social que é frequentado diariamente e durante um número significativo de horas, deve se constituir como um espaço privilegiado para práticas educativas que favoreçam a integridade de cada ser, que alimente relações fraternas entre os membros da espécie e que preservem a biodiversidade, a qualidade de vida pessoal, social e ambiental.

Porém, de acordo com o que fora explicitado nas recomendações das diversas conferências mundiais, observa-se que a prática da Educação Ambiental não se restringe apenas aos espaços escolares, pois é de responsabilidade de todos, ou seja, de entidades governamentais, não governamentais e da sociedade civil como um todo, conferindo-lhes direitos, porém atribuindo deveres para a preservação da qualidade de vida planetária.

\section{EDUCAÇÃO ESCOLAR E EDUCAÇÃO NÃO ESCOLAR}

A educação como prática social que faz parte do contexto geral da sociedade, assume diferentes modalidades. Nesse sentido há uma educação não intencional, informal, que se refere as influências do meio natural e social sobre o homem e interfere em sua relação com o meio social, como exemplo dessa modalidade educativa, podem-se citar os costumes, a religião, as leis, as ideias vigentes na sociedade, o tipo de governo e as práticas familiares. Tais fatores ou atos, nem sempre conscientemente intencionais, não institucionais, não planejados, assistemáticos, envolvem tudo o que impregna a vida social, como o ambiente e as relações socioculturais, e atuam sobre a formação das pessoas. (LIBÂNEO;OLIVEIRA ; TOSCHI ,2007)

Há ainda, a prática educativa intencional, que se caracteriza em educação não formal e educação formal. A prática educativa não formal diz respeito as atividades intencionais em que há relações pedagógicas com pouca sistematização ou estruturação, como ocorre nos movimentos sociais, nos meios de comunicação de massa, nos locais de lazer como clubes, 
cinemas e museus, entre outros. Enquanto a educação formal caracteriza-se por ser institucional, ter objetivos explícitos, conteúdos, métodos de ensino, procedimentos didáticos.

Tal modalidade não ocorre apenas na escola, local típico desse tipo de educação, mas também em locais em que a educação for intencional, estruturada, organizada, e sistematizada, como exemplos, há a educação de adultos, a educação sindical, profissional, que ocorrem fora da escola. (LIBÂNEO; OLIVEIRA; TOSCHI, 2007).

De acordo com o Artigo $2^{\circ}$ da Lei de Diretrizes e Bases n ${ }^{\circ} 9.394$ de 20 de dezembro de 1996, a finalidade da educação é: “ [...] dever da família e do Estado, inspirada nos princípios de liberdade e nos ideais de solidariedade humana, tem por finalidade o pleno desenvolvimento do educando, seu preparo para o exercício da cidadania e sua qualificação para o trabalho" (BRASIL, 1996, p. 01).

No período de 1995 a 1998, o Ministério da Educação elaborou os Parâmetros Curriculares Nacionais (PCNs), que vinculados a Lei de Diretrizes e Bases n ${ }^{\circ}$ 9.394/96, visam estabelecer diretrizes para o currículo do Ensino Fundamental servindo como referência nacional para a prática educacional e ações políticas no âmbito da educação, além de reafirmar a responsabilidade do Estado com o ensino. Os parâmetros dispõem os conteúdos a serem ensinados em dois grupos: áreas convencionais e os temas transversais (BOTON, 2010).

No que diz respeito à formação de cidadãos e preocupação com as relações sociais, o PCN apresenta o tema "Meio Ambiente" no volume 4 relativo a área de Ciências Naturais como conteúdo escolar, com objetivos de que os alunos sejam capazes de se perceber como integrantes, e agentes transformadores do ambiente, identificando seus elementos e as interações entre eles para contribuir ativamente para a melhoria do meio ambiente. E no volume 9, cujo tema transversal é Meio Ambiente e Saúde, a questão ambiental tem por finalidade contribuir para a formação de cidadãos conscientes, aptos para decidirem e atuarem na realidade socioambiental de um modo comprometido com a vida, com o bem-estar de cada um e da sociedade, local e global (BRASIL, 2000).

Com advento dos Temas Transversais estabelecidos pelos Parâmetros Curriculares Nacionais, a educação formal é contemplada, atualmente, com a possibilidade de ultrapassar o caráter informativo e passa a ter um caráter formativo; possibilitando a formação de hábitos, atitudes e comportamentos, capazes de sustentar a nova consciência ambiental (BRANCO,2003).

A Educação Ambiental não deve ser considerada como uma disciplina, mas sim como um trabalho integrado com as outras áreas do currículo e também com o contexto histórico e social de cada escola. Nesse sentido o interesse em 
se trabalhar as questões do Meio Ambiente deve estar presente em todos os aspectos do ensino, e estar ligado a todos os aspectos da vida ( ZEPPONE ,1999, p. 27).

Ainda que a Educação Ambiental também se efetive em contextos educativos não formais, as instituições de ensino têm um papel crucial para a formação de pessoas críticas, no que se refere a interações humanas com os demais seres do planeta. São as instituições escolares, nas quais as crianças passam a maior parte de seu tempo, que podem e devem, por meio de seus currículos e de sua própria gestão de ensino, tornar efetiva a Educação Ambiental (TIRIBA; PROFICE, 2014).

A Educação Ambiental não formal pretende provocar processos de mudanças sociais e culturais que visam obter do conjunto da sociedade tanto a sensibilização à crise ambiental e a urgência em mudar os padrões de uso dos bens ambientais, quanto o reconhecimento dessa situação e a tomada de decisões a seu respeito, caracterizando um movimento que busca produzir um novo ponto de equilíbrio, nova relação de reciprocidade, entre as necessidades sociais e ambientais (CARVALHO, 2008).

Embasadas na concepção de educação não formal e fundamentadas em diversos trabalhos na área de educação ambiental, optou-se por desenvolver uma pesquisa no sentido de contribuir para o desenvolvimento de uma educação formativa, motivo pelo qual apresentamos uma proposta de atividades direcionadas a Reserva Ecológica Amadeu Botelho. Entretanto por meio de adaptações estas podem ser aplicadas em outros ambientes educativos.

\section{RESERVA ECOLÓGICA AMADEU BOTELHO NO MUNICÍPIO DE JAÚ COMO MEIO PARA UM PROGRAMA DE EDUCAÇÃO AMBIENTAL}

A Reserva Ecológica Amadeu Botelho está localizada no município de Jahu, há aproximadamente 07 quilômetros do centro da cidade e 300 quilômetros da capital do Estado de São Paulo. Atualmente o proprietário da reserva é o Antônio Carlos Botelho Müller Carioba, um dos netos de Antônio Carlos ,que nasceu e cresceu na fazenda. Desde criança gostava da mata, e quem melhor a conhece. Seu desejo sempre foi preservá-la, como fizeram seu avô e seu bisavô. Em 1994 começou a trabalhar como administrador da propriedade, porém notava que havia caçadores entrando na mata, pessoas invadiam a área para coletar plantas medicinais, marcar o tronco das árvores, sendo que muitos deixavam lixo e até encontrava indícios de fogueiras. Com a aprovação e apoio dos proprietários decidiu fazer da área da mata uma reserva ecológica, a qual chamou de Reserva Ecológica Amadeu Botelho. Escolheu esse nome porque 
a mata era conhecida na cidade de Jaú como "Mata do Madeu", e porque quis fazer uma homenagem a seu bisavô Carlos Amadeu pelo seu espírito de conservação numa época em que poucos tinham essa visão preservacionista.

Em 1998 criou um Programa de Educação Ambiental, com o objetivo de conscientizar a população e proteger o ecossistema local. Em 27 de março de 2000, uma área de aproximadamente 142 hectares da mata, foi reconhecida como Reserva Particular do Patrimônio Natural (RPPN, Reserva Particular do Patrimônio Natural) (PESSOA, 2013).

Nesse sentido e reconhecendo a importância da diversidade da fauna e flora existente no local, idealizou-se uma proposta de intervenção pedagógica na Reserva Ecológica Amadeu Botelho no Município de Jaú, no intuito de sensibilizar e conscientizar crianças e jovens que frequentemente visitam o local, além de possibilitar a formação de valores e atitudes de cidadania em relação ao meio. Essas visitas geralmente são realizadas por alunos e professores de escolas públicas ou particulares, bem como crianças, jovens e adultos de entidades assistenciais, entre outros. Porém é pertinente salientar que de acordo com o grupo de visitantes, algumas adequações são necessárias, em função da faixa etária e do interesse do grupo, tratando-se, portanto, de uma proposta aberta.

\subsection{Na trilha da Educação Ambiental}

$\mathrm{Na}$ atualidade, é comum que crianças e jovens urbanos tenham perdido a conexão com as fontes naturais, sendo que o mundo virtual na contemporaneidade está mais imperativo que o mundo natural. No entanto, seguindo a trilha da Educação é possível ajudar a reconstruir essa conexão, possibilitando uma reflexão, um sentir, um agir sobre o contexto ambiental. A partir desses pressupostos têm-se algumas indagações: Quantas vezes olhamos sem ver, escutamos sem ouvir, nos alimentamos sem sentir o sabor dos alimentos, ou notamos alguns odores, mesmo que sejam agradáveis.

Partindo dessas premissas ,propõe-se, portanto, algumas ações na Reserva Ecológica Amadeu Botelho, que possibilitem o despertar pela riqueza do ambiente natural, com sua biodiversidade, relações e sua beleza em todo o seu contexto, ou seja, que por uma perspectiva de educação participativa e formativa o indivíduo e a coletividade possam despertar para a construção de valores sociais, adquirindo conhecimentos, desenvolvendo atitudes e competências voltadas para conquista da manutenção do ambiente, tão próximo de nós.

Como Dias (2004) enfatiza, as mudanças devem sempre começar dentro de cada um de nós. Após sensibilização, conscientização e reflexão sobre os hábitos, tendências e 
necessidades, pode-se de certa forma, através da adoção de novos comportamentos, dar a nossa contribuição para a diminuição da degradação ambiental e para a defesa e promoção da qualidade de vida.

\subsubsection{Atividade de ambientação}

Objetivo: Discutir sobre a biodiversidade presente no local, estabelecendo uma relação com a fauna e flora brasileira e a interdependência entre ambas.

Conteúdo: Biodiversidade local

Procedimento: Ao iniciar a visita de lazer e cultura no espaço denominado de Centro de Educação Ambiental Curumim, as crianças participam de uma palestra ministrada pelo responsável da fazenda e/ou monitor, fazendo um breve relato histórico sobre a Reserva e expondo rochas, frutos, sementes e imagens de algumas espécies da fauna brasileira, que são encontradas na mata.

Conforme Dário (2004) essa abordagem é pertinente, pois a fauna é muito importante por atuar de forma crucial na manutenção e restauração dos ambientes naturais, pois são eles que dispersam as sementes para germinação das árvores e controlam populações de espécies que quando em excesso, podem ser prejudiciais as lavouras e criações. Cada pequeno animal tem sua função específica na natureza e a sua ausência acarreta em grandes prejuízos para toda a humanidade.

Ainda no Centro de Educação Ambiental Curumim nessa fase de ambientação propõese uma atividade denominada de "Que animal sou eu?" (CORNELL, 1996) (adaptado).

Sugere-se seleção e a amostragem de imagens de algumas espécies da fauna brasileira presentes na mata, bem como dos animais mais conhecidos e mais fáceis de se caracterizar, enfatizando características relevantes de cada uma das espécies. Recomenda-se que as crianças conheçam por fichas fotográficas outras diferentes espécies e sua importância para o contexto ambiental, no intuito propiciar condições para que relatem a respeito de seus animais de estimação, como por exemplo, a que espécie pertencem, qual o tipo de alimentação e moradia, como é feita a higiene, sobre as condições de saúde deles, etc. (CETESB,1987).

Pode-se promover uma discussão estabelecendo uma relação entre os animais de estimação, e os selvagens presentes na fazenda, questionando de que maneira cada animal domésticos e relaciona com a criança no dia a dia, e qual a importância de cada espécie silvestre para a natureza e para o homem. 


\subsubsection{Atividade para conceituação}

Objetivos: Promover conceitos sobre as características dos animais existentes na Reserva, relacionando com a fauna brasileira.

Despertar o entusiasmo, a curiosidade pelo ambiente e estimular a interação entre os colegas.

Conteúdo: Espécies animais e suas características

Procedimento: Logo após esta exposição, as crianças devem se dirigir a área externa do Centro de Educação Ambiental Curumim. Propõe-se que os monitores (de acordo com o número de crianças ou jovens) deverão dividir a turma em dois grupos heterogêneos (Grupo A e Grupo B). Cada grupo deverá escolher um participante para ser o "Adivinha". Para essa dinâmica deve-se utilizar as fichas fotográficas utilizadas na atividade de ambientação. O aluno do grupo escolhido como "Adivinha" deverá selecionar uma ficha que será fixada em suas costas, de maneira que ele não possa ver em qual animal se transformou, mas para o grupo, isso é permitido. Dada a largada, o adivinhador deverá começar a perguntar ao grupo sobre às características do animal, ou seja, em relação ao modo de vida, sua alimentação, hábito diurno ou noturno, tipo de revestimento do corpo, se voa, rasteja ou pula, a fim de descobrir em qual animal ele se transformou. Para cada pergunta que o "adivinha" fizer, o grupo só poderá responder com Sim, não ou talvez. A adivinha de acordo com as dicas dos colegas, terá até três tentativas para acertar o nome do animal. Ao final comparando-se o número de acertos da "adivinha" de cada grupo, vencerá aquele em que acertou maior número de animais (CORNELL, 1996) (adaptado).

\subsubsection{Atividade de sensibilização}

Objetivos: Oportunizar momentos para a sensibilização sobre os recursos naturais existentes na Reserva e os benefícios para toda comunidade de entorno.

Ressaltar sobre as espécies nativas da flora brasileira, especificamente das árvores presentes na mata e sua importância para a manutenção da fauna local e possibilitar a dramatização e expressões corporais.

Conteúdo: As plantas como reguladores da umidade do ar.

Procedimento: Antes de iniciar a trilha, as crianças devem ser alertadas de que alguns cuidados devem ser tomados, como ficar atento por onde anda e pisa, silêncio para não afugentar animais, não retirada de material da mata e a importância de permanecerem juntos, 
para que possam participar intensamente das atividades que lhes serão propostas.

Adentrando na mata é fundamental chamar-lhes a atenção para o frescor, o aroma, a presença de flores e insetos, o ruído existente no local, a presença dos animais e dos seres em decomposição, a diversidade da flora e da fauna, a transparência da água do córrego, sobre o abrigo dos animais, a inter-relação entre flora e fauna, a polinização, ou seja, tecer comentários a partir do que estiver vivenciando no momento.

Ao final da trilha, para aguçar a curiosidade dos visitantes, eles encontrarão um pequeno galho de árvore com folhas, preso em um saco plástico. Os monitores devem questionar: O que um saco plástico está fazendo "prendendo" esse pequeno galho?

$\mathrm{O}$ objetivo destes questionamentos é demonstrar às crianças de maneira concreta a importância das plantas em relação a umidade e a purificação do ar para a atmosfera. O saco plástico deve ser bem amarrado de modo a não permitir a entrada e saída de gases e deve ser deixado por vinte e quatro horas antes do horário da visita do grupo. Após esse período verificase que haverá uma pequena quantidade de água em seu interior. Mais uma vez os monitores enfatizarão a importância das plantas para a natureza e para nossa vida, assim, sugere-se uma dinâmica divertida, chamada "Eu sou uma árvore" (DIAS, 1994).

Os monitores deverão eleger uma criança por vez para representar uma árvore através da comanda que dará.

De acordo com as instruções dos monitores, a criança escolhida deverá se posicionar em um ponto onde todos possam vê-la, e assim, um aluno por vez, serão desafiados e envolvidos num mundo do faz-de-conta, para representarem as reações de uma árvore quando:

- Um vento suave balança as folhas;

- Quando há fogo na floresta;

- Tem um rato roendo o tronco;

- Pessoas atiram pedras nos frutos;

- Tem ocorrência de chuva;

- Pessoas arrancam as folhas das plantas;

- Pessoas fazem marcas no tronco;

- Passarinhos fazem ninhos nos galhos;

- A árvore for plantada e estiver crescendo;

- Uma pessoa está cortando-a com um motosserra.

É importante que todos participem, e durante ou após a representação questionar as crianças sobre quais ações são boas ou ruins para a árvore e para o Meio Ambiente. 
Para Torres (2011) a flora é representada por um conjunto de vegetais de uma determinada área e está relacionada com as funções de regulação ambiental, no armazenamento de água e energia. A sucessão ecológica é o fenômeno que ocorre nos ecossistemas após a destruição parcial da comunidade original (como por exemplo, a derrubada de florestas) onde ocorre uma progressiva mudança na composição florística da floresta. Nestes locais há uma mudança negativa nas condições ambientais, como por exemplo, o aumento da quantidade de luz, da temperatura do solo e do ar, e decréscimo da umidade relativa (importante para a preservação da mata e vida dos animais).

Mediante este aspecto, é importante enfatizar sobre a importância da preservação do ambiente natural; a conservação das árvores existentes nas matas e florestas, bem como nas cidades, no sentido de manter a umidade do ar, o nível de poluição, abrigo e alimentação para os animais, etc.

\subsubsection{Atividade de Responsabilidade Ambiental}

Objetivo: Estimular a consciência ética e a formação de valores para assumir a responsabilidade ambiental, no meio em que está inserido.

Conteúdo: Responsabilidade ambiental.

Procedimento: Ao se tratar de responsabilidade ambiental, as crianças farão a próxima dinâmica na horta da fazenda. É importante que elas conheçam os produtos cultivados naquele local e os cuidados que devem ser tomados para o seu desenvolvimento.

Inicia-se a conversa discutindo sobre a utilização de agrotóxico e fertilizantes químicos usados nas plantações, e os efeitos desses produtos para a saúde humana, podendo causar câncer, desordens do sistema nervoso, defeitos congênitos e esterilidade masculina (AZEVEDO, 2006).

Outro aspecto a ser abordado é sobre a germinação das sementes com a utilização de produtos da compostagem realizada no local, em que restos de vegetais considerado lixo, é transformado em adubo orgânico e utilizado na horta.

Também é ressaltado que na horta pode-se ter problemas com pragas ou as plantas podem adoecer. Por se tratar de horta orgânica, é considerável ressaltar sobre como é realizado o controle dessas pragas naquele ambiente. "É importante citar como devemos controlar, no caso das pragas recomenda-se a catação desses animais, e no caso das plantas doentes o controle mais eficaz é a eliminação das mesmas” (FERNANDES, 2007, p. 19).

$\mathrm{Na}$ roda de conversa também é interessante estimular a curiosidade das crianças a 
respeito do conceito de hortaliças: grupos vegetais cultivados em horta, em que partes como raízes, caules, folhas, flores, frutos e sementes, servem de alimento para nós. Pode-se também aguçar o sentido do paladar, fornecendo-lhes folhas de hortelã ou folhas de outras espécies para as crianças provarem.

Utilizando o adubo proveniente da compostagem realizada na fazenda, as crianças farão o plantio de sementes previamente selecionadas. Orientadas pelos monitores, e utilizando embalagens descartáveis como garrafa pet, caixas de leite, caixas de ovos, entre outros, de forma individual, as crianças farão o plantio e receberão instruções sobre o procedimento de cuidado e manutenção para mesmas. Elas terão como dever, levar os frascos com sementes para casa para cultivá-las, seguindo as orientações dadas pelos monitores durante a ação (ADAMS, 2011).

Após o encerramento das atividades propostas, numa área verde próximo à sede da Fazenda, sugere-se que se faça uma reflexão sobre os aspectos abordados durante o passeio.

\subsubsection{Atividade de relaxamento}

Objetivo: Alcançar um estado de relaxamento físico e mental e refletir sobre as observações e atividades desenvolvidas durante o caminhar pela trilha.

Conteúdo: Valores, atitudes e um mundo melhor.

Procedimento: Esta atividade é denominada como "Atividade de relaxamento" sugerida por (ADAMS, 2011), porém para ser aplicada de acordo com o objetivo proposto, sofreu adaptações, passando a ser denominada como "Eu posso...", e será realizada no pátio do Centro de Educação Ambiental Curumim.

A proposta é que se inicie a dinâmica deixando as crianças bem relaxadas. Propõe-se que elas formem um círculo (sem dar as mãos), fechem os olhos, e passe alguns minutos de olhos fechados, sentindo a brisa, o calor do Sol e ouvindo os ruídos da natureza. Nesse momento o monitor deverá fazer um feedback de todo o trajeto percorrido, de tudo o que foi feito, falado, sentido e discutido.

Em seguida, propõe-se que o monitor peça às crianças que cada um pense em algo que gostaria de mudar no mundo. Neste caso, mudar em relação as atitudes do homem, que são consideradas negativas para o meio ambiente. O monitor deve estar no centro do grande círculo, e então ele diz "Eu posso cuidar mais das árvores..." e aponta para uma das crianças, para que esta fale o que se pode fazer. Espera-se que a criança fale o que foi aprendido durante o passeio, como "Eu posso cuidar mais das árvores deixando de fazer marcas no tronco" ou "Eu posso 
cuidar mais das árvores deixando de jogar pedras nos frutos", eu posso cuidar mais dos animais, entre outros (ADAMS, 2011).

Após o participante ter escolhido o que dizer, este se senta, e o monitor prossegue de forma dinâmica apontando para outra criança, para que esta possa socializar aspectos relacionados a outros assuntos abordados, como "Eu posso proteger os animais...", "Eu posso ter uma alimentação saudável...", "Eu posso cuidar mais da natureza...”, entre outros. O monitor deve apontar para a crianças, até que todos tenham participado.

Assim, de forma divertida, todas as crianças podem comemorar o passeio, contemplando e agradecendo a natureza, e posteriormente no Pátio do Centro de Educação Ambiental Curumim degustar guloseimas elaboradas com produtos da própria reserva.

\section{CONSIDERAÇÕES FINAIS}

Ao observar a evolução histórica da Educação Ambiental, nota-se o quanto ela evoluiu. No início dos anos 50, a preocupação com a devastação planetária já existia, porém não haviam subsídios legislativos para efetivar a melhoria por essa deficiência. A partir de 1972 com a Conferência de Estocolmo, a temática ambiental passou a ser discutida e foi retomada com a Conferência do Rio-92, que teve como objetivo examinar a situação ambiental do mundo e a prospectiva da educação como um meio para minimizar essa crise ambiental.

Com base nesses acontecimentos a Educação Ambiental adquiriu força no âmbito local e global, extrapolando os limites da escola. Atualmente esse tema entra nas agendas de governos, movimentos sociais, meios de comunicação, empresas, entidades religiosas, entre outras, pois essa questão, além de fazer parte das preocupações do cotidiano, nos leva a uma expectativa em relação ao futuro do planeta.

No entanto ainda que a Educação Ambiental também se efetive em contextos educativos não formais, as instituições de ensino têm um papel crucial para a formação de pessoas críticas, no que se refere a interações humanas com os demais seres do planeta.

São as instituições escolares, nas quais as crianças passam a maior parte de seu tempo, que podem e devem, por meio de seus currículos e de sua própria gestão de ensino, tornar efetiva a Educação Ambiental.

A aprendizagem é conquistada, não só através do ensino teórico, mas fundamentalmente, por meio de atividades práticas, com vistas a melhoria da percepção do indivíduo com relação a si mesmo, com relação ao ambiente e à percepção dele no ambiente.

Com a elaboração deste trabalho pretende-se contribuir com os programas de Educação 
Ambiental existente na Reserva Ecológica Amadeu Botelho, constituindo um meio de educação não formal no intuito de estimular atitudes preservacionistas, pelas quais o indivíduo possa perceber-se como parte integrante do meio e adquirir novas formas de conduta em relação ao meio ambiente. Ressalta-se também que esse programa pode ser realizado em outros ambientes naturais, bem como para um público alvo distinto, desde que sejam feitas as devidas adequações.

A Educação Ambiental é uma ferramenta capaz de promover valores, não constituindo apenas um meio para transmitir informações, mas refere-se a um processo que envolve mudança de paradigma, possibilitando que o indivíduo aprenda e incida sobre sua própria identidade e posturas diante do mundo. Oportuniza o desenvolvimento de habilidades como mais cooperação, respeito e com um olhar diferenciado em relação ao mundo. Nesse contexto podem-se ter expectativas sobre a recuperação do meio ambiente, ou a esperança de minimizar a destruição dos recursos naturais.

Conclui-se que houve uma evolução com relação à legislação sobre Educação Ambiental e que esta deve ser desenvolvida pela educação formal em todos os níveis de ensino, em caráter permanente e de forma interdisciplinar, bem como pela educação não formal e informal desenvolvidas pelos diferentes segmentos da sociedade. Os espaços naturais constituem-se como espaços educadores que contribuem para construção emocional e intelectual do indivíduo e favorece o processo de transformação social, possibilitando uma melhoria da qualidade de vida a todos.

\section{REFERÊNCIAS}

ADAMS, B. G. Coletânea de práticas para educação ambiental: para professores da educação infantil e anos iniciais do ensino fundamental. Novo Hamburgo: Apoema, 2011.

AZEVEDO, E. Alimentos Orgânicos: ampliando conceitos de saúde humana, social e ambiental. Tubarão: Unisul, 2006. In: O perigo dos agrotóxicos. Disponível em: http://www.hortadavovo.com.br/o-perigo-dos-agrotoxicos/. Acesso em: 18 out. 2017.

BOTON, J. M. et al. O meio ambiente como conformação curricular na formação docente. Revista Ensaio. Belo Horizonte. vol. 12 n. 03, 2010. p. 41-50.

BRANCO, S. Educação Ambiental: Metodologia e Pratica de Ensino. Rio de Janeiro: Dunya. 2003.

BRASIL. Ministério da Educação. Lei de Diretrizes e Bases da Educação Nacional. Lei no 9394, de 20 de dezembro de 1996.Estabelece as diretrizes e bases da educação nacional. Brasília, 1996. Disponível em: http://www.planalto.gov.br/ccivil_03/leis/L9394.htm. Acesso 
em: 14 ago. 2017.

BRASIL. Constituição Federal de 1988. Constituição da República Federativa do Brasil. Brasília, 1988. Disponível em: http://www.planalto.gov.br/ccivil_03/constituicao/constitui ção.htm. Acesso em: 04 ago. 2017.

BRASIL. Parâmetros Curriculares Nacionais: Ciências Naturais. Secretaria de Educação Fundamental. 2. ed. Rio de Janeiro: DP\&A, 2000.

BRASIL. Parâmetros Curriculares Nacionais: Meio Ambiente e Saúde. Secretaria de Educação Fundamental. 2. ed. Rio de Janeiro: DP\&A, 2000.

CARVALHO, I. C. M. Educação Ambiental: a formação do sujeito ecológico. 3. ed. São Paulo: Cortez, 2008.

CETESB. Conhecendo o meio ambiente: material de apoio à educação ambiental. São Paulo: CETESB, 1987.

CORNELL, J. Brincar e aprender com a natureza: guia de atividades infantis para pais e monitores. São Paulo: SENAC, 1996.

DÁRIO, F. R. A importância da fauna na dinâmica das florestas. 2004. Disponível em: http://port.pravda.ru/news/cplp/brasil/26-07-2004/5751-0/. Acesso em: 16 out. 2017.

DIAS, G. F. Educação Ambiental: princípios e práticas. 9. ed. São Paulo: Gaia. 2004.

DIAS,G.F. Elementos para capacitação em educação ambiental. Ilhéus: Editus, 1999.

DIAS,G.F. Atividades Interdisciplinares de Educação Ambiental. São Paulo: Global, 1994.

FERNANDES, M. do C. de A. et al. Tudo o que você precisa saber para ter uma horta. 2. ed. Niterói: PESAGRO-RIO, 2007. Disponível em: http://www.espacodoagricultor.rj.gov.br /pdf/hortalicas/horta.pdf. Acesso em: 18 out. 2017.

GARCIA, W. E. Educação: visão teórica e prática pedagógica. McGraw-Hill. São Paulo, 1977.

LIBÂNEO, J. C; OLIVEIRA, J. F. de; TOSCHI, M. S. Educação Escolar: políticas, estrutura e organização. 4. ed. São Paulo: Cortez, 2007.

MAIAKOVSKI, V. Implantação da Educação Ambiental no Brasil: novas leis, para o ambiente e a educação. Brasília/DF: Coordenação de Educação Ambiental do Ministério da Educação e do Desporto.1998. Disponível em: http://www.dominiopublico.gov.br/download /texto/me001647.pdf.. Acesso em: 20 mai. 2017.

ORGANIZAÇÃO DAS NAÇÕES UNIDAS (ONU). Declaração Universal dos Direitos Humanos, de 10 de Dezembro de 1948. Disponível em :http://unesdoc.unescoorg/images/0013/ 001394/139423por.pdf. Acesso em: 02 set. 2017. 
UNESCO. La Educacion Ambiental. Las grandes orientaciones de la Conferência de Tbilisi. Paris, 1980. Disponível em: http://unesdoc.unesco.org/images/0003/000385/038550so.pdf Acesso em: 15 nov. 2017.

PEDRINI, A. de G. Educação Ambiental: reflexões e práticas contemporâneas. Petrópolis RJ: Vozes. 1997.

PESSOA, R. Plano de manejo da Reserva Ecológica Amadeu Botelho. 2013. Disponível em: http://www.icmbio.gov.br/portal/images/stories/docs-planos-demanejo/rppn_amadeu_ botelho_pm.pdf. Acesso em: 28 ago. 2017.

STRONG, M. Implantação da Educação Ambiental no Brasil: no dia seguinte. Brasília DF: Coordenação de Educação Ambiental do Ministério da Educação e do Desporto. 1998. Disponível em: http://www.dominiopublico.gov.br/download/texto/me001647.pdf. Acesso em: 20 mai. 2017.

TIRIBA, L. O Convívio com a natureza é um direito das crianças? Reflexões sobre educação, escola e divórcio entre seres humanos e natureza. In: SILVA, A. M. M.; TIRIBA, L. Direito ao Ambiente como Direito à Vida: desafios para a educação em direitos humanos. São Paulo: Cortez, 2014. p. 113-139.

TIRIBA, L; PROFICE, C. O Direito Humano à Interação com a Natureza. In: SILVA, A. M. M.; TIRIBA, L. Direito ao Ambiente como Direito à Vida: desafios para a educação em direitos humanos. São Paulo: Cortez, 2014. p. 47-77.

TORRES, C. Flora - Sua importância no ecossistema. 2011. Disponível em: http://cesara torres.blogspot.com.br/2011/05/flora-sua-importancia-no-ecossistema.html. Acesso em: 16 out. 2017.

ZEPPONE, R. M. O. Educação Ambiental: teoria e práticas escolares. Araraquara: JM, 1999 